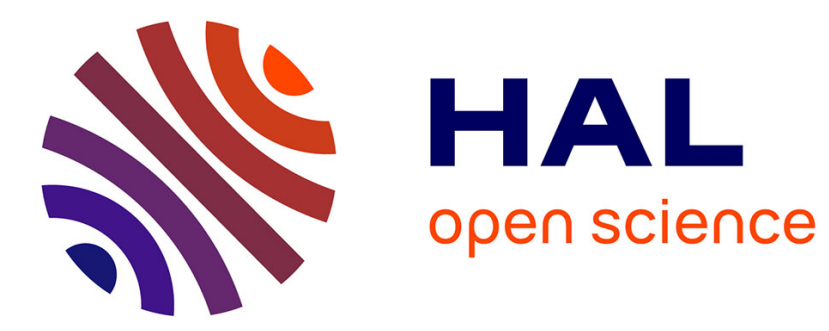

\title{
Towards a better management of complex emergencies through crisis management meta-modelling
}

\author{
Matthieu Lauras, Sébastien Truptil, Frederick Benaben
}

\section{To cite this version:}

Matthieu Lauras, Sébastien Truptil, Frederick Benaben. Towards a better management of complex emergencies through crisis management meta-modelling. Disasters, 2015, 39 (4), pp.687-714. 10.1111/disa.12122 . hal-01208000

\section{HAL Id: hal-01208000 \\ https://hal.science/hal-01208000}

Submitted on 1 Oct 2015

HAL is a multi-disciplinary open access archive for the deposit and dissemination of scientific research documents, whether they are published or not. The documents may come from teaching and research institutions in France or abroad, or from public or private research centers.
L'archive ouverte pluridisciplinaire $\mathbf{H A L}$, est destinée au dépôt et à la diffusion de documents scientifiques de niveau recherche, publiés ou non, émanant des établissements d'enseignement et de recherche français ou étrangers, des laboratoires publics ou privés. 


\section{Towards a better management of complex emergencies through crisis management meta-modelling}

\section{Matthieu Lauras, Sébastien Truptil and Frédérick Bénaben ${ }^{1}$}

Managing complex emergencies situations is a complicated task, mainly due to the heterogeneity of the partners involved and the critical nature of such situations. Whatever approach is adopted to support this objective, one unavoidable issue is knowledge management. In the context of our research project, gathering, formalising and exploiting all the knowledge and information concerning a given crisis situation is a critical requirement. This article presents some research results concerning this specific topic: from a theoretical point of view, the generic dimensions of crisis characterisation are defined while from a technical point of view, we describe a software solution able to collect that knowledge (based on meta-models and ontologies). This is used to confront the characteristics of the situation (context) with characteristics of the resources (relief system) in order to design a suitable response. Finally, an illustrative example concerning a crash between a tanker truck and a train is described.

Keywords: crisis management, knowledge-based reasoning, meta-modelling, ontology

\section{Introduction and contribution statements}

In a crisis context (such as a natural crisis, crash, conflict, industrial accident), different actors from different organisations (medical units, police, non-governmental organisations) have to work simultaneously and in a hurry. Thus, they need not only to coordinate their objectives and their actions, but also share parts of their resources, information and processes in order to achieve a common goal (according to the people, goods and infrastructures in danger). In this context, the integration of partners is a crucial step to successful crisis reduction. Our aim is to propose a solution to this need of integration of partners by means of knowledge sharing.

One main challenge regarding the management of complex emergencies is that it has to adapt to the inevitable changes in the nature of the crisis and remain dedicated to the - possibly changing - group of partners involved in working on the 
crisis. This raises several issues, such as how to coordinate stakeholders, but above all it requires the definition of a common universe of discourse (in the crisis domain), which is essential to solving the various semantic conflicts that are bound to occur between the participants and their information systems.

This paper addresses this issue by making proposals in terms of crisis ontology. Ontology promotes and facilitates interoperability among information systems, intelligent processing by agents and shared reuse of knowledge among systems (Pinto and Martins, 2004). It is particularly useful in a crisis situation and in a collaborative context. But as Zhang et al. (2002) explain, in such a context, information and knowledge are widely distributed and the resources are not efficiently organised and utilised during operations. A conceptualisation is thus required to make the knowledge of the relations among the relief stakeholders explicit. Conventional wisdom tells us that no two crises are the same. The nature, the number and the incentives of stakeholders vary tremendously and each crisis requires its own management processes. On the other hand, however, the way crises impact victims or business processes may well be similar, and responses are often transferrable between crises, at least in part (Othman and Beydoun, 2010).

This research work aims to provide a shared and common understanding of the management of crises and their collaborative processes, in order to design and monitor future decision-making support tools and/or crisis management information systems. Practically, the paper focuses only on the response phase ${ }^{2}$ of a crisis and develops a crisis management unified modelling language (UML) ${ }^{3}$ meta-model and its corresponding ontology web language (OWL). Being in a formal format, the OWL ontology provides partners with the means for acquiring, sharing and reasoning about crisis information and knowledge. Our results constitute a continuation of the French research project called ISyCri (Interoperability of Systems in Crisis Situations), which was carried out between 2007 and 2010. The final objective of this research project was to provide partners involved in crisis situations with an information technology interoperability system able to federate their respective heterogeneous and autonomous information systems into a global system of systems acting to reduce the crisis through an adequate collaborative process.

In the following pages we first draw up a crisis-ontology state-of-the-art and explore the concepts of ontological engineering. This leads us to propose an original crisis meta-model that extends the limits of previous works and can be used to design and control future response solutions. We then develop an application case to 
illustrate the dimensions of our proposal and to discuss its advantages and limits. Finally, we present conclusions and discuss opportunities for further research.

\section{Background and research scope}

For many years, ontologies have been developed for different purposes and cover various domains such as medicine and tourism. Here we intend to develop an ontology that covers the crisis management domain, one able to support the design and the monitoring of an accurate relief response.

\section{Ontology and meta-modelling}

Over recent decades, there had been a huge growth in meta-modelling and ontology uses (see Henderson-Sellers, 2011; Sugumaran and Storey, 2002; Uschold, 2005). Although many authors (Henderson-Sellers, 2011; Ruiz and Hilera, 2006) remark on a continuing confusion between the terms meta-model and ontology, we can note a difference between these two concepts. Guizzardi (2005) defines a model as an abstraction of reality according to a certain conceptualisation. A meta-model is then a 'model of models' (OMG, 2003) that: (i) describes a domain that is representative of more than one instance in a less abstract domain and (ii) is the core of a modelling language used to describe those instances (Bataille and Castellani, 2001; HendersonSellers, 2011). On the other hand, ontology is a formal explicit specification of a shared conceptualisation for a domain of interest (Gruber, 1993). Ontology represents knowledge that can be used and reused in order to facilitate the comprehension of concepts and relations in a given domain as well as the communication between different domain actors. Henderson-Sellers (2011) proposes a very instructive study on potential use of meta-models and their associated ontologies. It appears that there are two kinds of ontology that are useful for engineering:

- Domain ontologies, which are used to create common vocabulary for a specific application domain.

- Meta-ontologies, which are equivalent in nature to the meta-model of a modelling language and thus encapsulate the concepts needed for creating domain ontologies. 
Our study clearly focuses on meta-ontologies. Consequently, we do not develop any semantic contribution regarding the crisis domain in this paper. Our ambition is only to propose some original contributions regarding the structuration of crisis concepts and relations between them. Based on these inputs, future research works should allow developing operational and innovative tools able to support crisis management.

To build such a crisis ontology, many authors such as Colomb and Ahmad (2010) and Silva Parreiras and Staab (2010) have suggested: (i) using a UML class model to build the meta-model; (ii) using an OWL representation language to create the ontology on the basis of a previous meta-model. Silva Parreiras and Staab (2010) even proposed an integrated use of both modelling approaches in a coherent framework. Nevertheless, in this research work, we have made the choice to maintain separate representations to capture information about different views of systems on the one hand (UML part), and to provide a class definition language for ontology on the other hand (OWL part).

\section{Crisis ontology}

At the beginning of this research project in 2007, the literature review on existing ontologies showed that very few have attempted to represent crisis management knowledge in reusable form (Asghar et al., 2006; Sanjay and McLean, 2003; Slobodan and Sajjad, 2005). These ontology meta-models started to unify the terminology, sharpening the definition of terms and their semantic relationships. But at that time, this work remained in its infancy, and, above all, was not substantial enough to be employed for the re-use of ontology.

According to Pinto and Martins (2004) and Sugumaran and Storey (2002), ontology can be built from scratch or by means of re-use of previous knowledge. Considering the weakness of knowledge from existing sources in 2007, we decided to build our own ontology from scratch.

Since then, several research works have produced fledged meta-models, such as Bagheri and Ghorbani (2010), De Nicola et al. (2011), Kruchten et al. (2008), Othman and Beydoun (2010) and W3C Incubator Group (2008). The research work of Othman and Beydoun (2010) is probably the most mature, because it is based on 10 previous crisis meta-models and validated through 20 crisis models. In their paper, the authors propose a meta-model composed of four complementary packages corresponding to the four phases of the crisis cycle time: mitigation, preparedness, response and 
recovery. This meta-model unifies, facilitates and expedites access to crisis management expertise. Nevertheless, this proposal has several limitations:

- The majority of the 10 previous meta-models used are not formal (like a UML class diagram, for instance) and the associated extraction is not really explained.

- The proposal tackles the whole lifecycle of crisis and consequently cannot really go into the detail of each phase.

- The extraction of general concepts relates to a specific kind of crisis, such as a cyclone, and not to a general kind of crisis.

- The meta-model is not instantiated in order to create a concrete ontology (the work stops at the meta-model step).

On the other hand, authors such as Bagheri and Ghorbani (2010) and De Nicola et al. (2011) have developed meta-model ontologies dedicated to a specific kind of crisis, which is the critical infrastructure (CI) crisis. A CI is a network of independent manmade systems and processes that functions collaboratively and synergistically to produce and distribute a continuous flow of essential goods and services. In Bagheri and Ghorbani (2010), for instance, five meta-models are proposed to characterise various aspects of an infrastructure network such as managerial, structural and organisational aspects. The authors describe their meta-models through a UML profile with the aim to completely describe the CI domain and its interdependencies.

Of course, this proposal does not completely cover our study perimeter, which potentially includes any ecosystem and any sort of crisis, and which is focused on the only response phase of the crisis lifecycle. Nevertheless, their proposals, and equally those of Othman and Beydoun (2010) must be considered as very interesting complementary angles for our own research. Indeed, we have decided to confront our proposal to these related works in order to improve the overall result.

\section{Ontology engineering}

Several authors such as Sugumaran and Storey (2002) or Pinto and Martins (2004) have tried to structure the creation, use and management of ontologies. To build our ontology, we have chosen to use the ENTERPRISE methodology. This methodology is composed of four steps (Uschold and King, 1995): 
1. Identify the purpose and scope: Identify why the ontology is built, its intended uses, and (possibly) a range of intended users.

2. Build the ontology:

i. Capture knowledge:

a. Identify key concepts and relationships in the domain.

b. Produce text definitions for such concepts and relationships.

c. Identify terms to refer to such concepts and relationships.

ii. Code knowledge:

a. Organise concepts in a hierarchical way.

b. Transform the conceptual description into a formal model.

iii. Reuse appropriate knowledge from existing ontologies.

3. Evaluate: Use Gomez-Pérez et al. (1995) criteria.

4. Document: To avoid barriers to knowledge sharing.

This methodology includes several techniques, methods and guidelines, particularly regarding the phase of ontology design. The first step of the ontology-building phase consists in conceptualising and defining the concepts that are more highly connected to other concepts, because these are the most difficult to define correctly and accurately. Concepts are defined precisely and with a lot of attention, but in an informal manner. The second step of the ontology-building phase consists in transforming the previous knowledge into formal models. To do this, as suggested by Colomb and Ahmad (2010) and Silva Parreiras and Staab (2010), UML class diagrams and OWL have been chosen as ontology representation languages. The third step of the ontology-building phase consists in populating the obtained architecture with concrete knowledge.

The steps followed and the meta-model obtained, including its concepts and the relations between them, are presented in detail in the next section.

\section{Crisis management ontology building}

Identification of the purpose and scope

The purpose and scope should be defined according to three main questions:

1. What are the potential users of the ontology?

2. Why the ontology is built? 
3. What are the intended uses of the ontology?

There are different types of actors in a crisis-response emerging ecosystem. First, there are actors in the field, using their specific abilities (for example, to perform business activities such as evacuating injured persons or fixing a road). Second, there are the heads of these actors in the field, potentially grouped into a crisis cell with a single authority. Each head is in charge of, first, the activities of actors in the field, and secondly, the transfers of information inside the crisis cell. Although the actors have the same global shared aim, they are not dealing with the same problems. This results in communication and the exchange of information between the crisis stakeholders being insufficient to provide each member with a global view of the crisis. This is why the global French research ISyCri project focuses on this question of coordination inside the crisis cell.

The usual perception of hazard and crisis, together with the division of knowledge, implies building a shared knowledge-management system, based on the representation and the characterisation of a crisis. As discussed previously, in a crisis context, such an ontology should allow dealing with the problem of revealing and sharing the implicit and explicit crisis management knowledge. A dedicated ontology can be considered as an unavoidable first step to manage the design of information systems or decision-support systems dedicated to the crisis management. As discussed in the background section above, there is no tool available in the current literature except for a few regarding specific kinds of crises.

Based on the current research work, the results should be exploited in order to develop advanced crisis management tools able to support the management of the coordination, the agility or the efficiency of crisis responses. These systems might be considered as the final objective and the ontology as the necessary prerequisite. Other potential use could consist in transforming the meta-ontology proposed in this paper in a domain ontology (that is, with semantic content). This should be very helpful considering that each organisation - each actor-possesses its own knowledge, with its own semantic, usually limited to its core activity. However, even if all actors own all the knowledge of the domain collectively, none of them will master the whole knowledge or its boundaries individually. 
In order to facilitate the readiness of this section, a table with the definition of all the concepts we used in our final proposition is presented as an Appendix.

\section{Capture knowledge: crisis management knowledge gathering}

\section{Crisis definitions:}

The notion of crisis is a manifest component of our research project. In this paper the word crisis is used to qualify a serious threat that affects the basis structures or values and fundamental standards of a social system, which, in a situation of strong pressure and high uncertainty, requires that crucial decisions are taken (Rosenthal and Charles, 1989). According to this definition, it now seems logical to link the concept of crisis with the concept of risk. The notion of risk is very intuitive but its definition is not. We define the risk as the possibility of the occurrence of an event having positive or negative consequences. Two dimensions characterise risk: its probability and the measure of its potential effects (but note that danger exists continuously but risk appears only if there is exposure to a danger), a concept inspired by Lagadec (1992). This definition meets the $\mathrm{PRIM}^{4}$ vision that defines a crisis as the realisation of a major risk, due to the occurrence of a specific event and the presence of affected stakes. We believe that the happening of the specific event must be correlated with the presence of a danger. Danger exists in a continuous timeline but risk only occurs when there is exposure to a danger. It is crucial to note that if damage can be considered as an obvious and implicit component of a crisis, it is not the factor that implies the categorisation of a situation as a crisis. It is rather the unpredictability and the associated loss of control that are the initial factors in crisis identification.

Finally, we define a crisis as linked to the perception of an abnormal situation, which is a break in the expected evolution of the situation (standard, planned or at least acceptable) of the world or part of the world concerned by the phenomenon (the studied system). A crisis may evolve and change and could be characterised through three dimensions: its gravity (damage measurement), its complexity (type of crisis, involvement of human responsibility) and its perimeter (the size of the studied system).

\section{Crisis typology:}

The literature lists various kinds of crises that can affect an organisation. These kinds of crises are classified differently according to the authors: by nature, by hazard event, 
by speed of action or by intensity. We have adopted a classification following two main components:

- The nature (Kovoor-Misra, 1995): technical, human, political, legal, ethical or economic crises and natural disasters.

- The hazard event (Tomasini and Van Wassenhove, 2009): sudden-onset crisis or slow-onset crisis.

Our study is focused on sudden crises, whatever their nature (for example, we do not deal with pandemic or durable economic crises).

\section{Crisis dynamic:}

This abnormal situation, which occurs suddenly and impacts an (eco)system with unacceptable consequences, is a complex and dynamic phenomenon. It constitutes a threat to the survival of an organisation and its members, which gives little time to react, and which leads to an adaptation of the system (Jacques and Gatot, 1997). These points underline the fact that it is necessary to make decisions in a crisis. This dynamic aspect of the considered ecosystem implies dealing with the crisis management through a dedicated cell of actors in charge of the crisis response. Tomasini and Van Wassenhove (2009) consider two special factors to explain this very particular dynamic:

- A factor of gravity is a special danger that may imply the modification of the crisis gravity.

- A factor of complexity is a special danger that may imply the modification of the crisis complexity or even create another pole to the crisis (multipolar crisis).

In the literature, there are a lot of models that allow understanding the lifecycle of crisis management such as the traditional model, expand and contract model, Kimberly's model, Tuscaloosa model, circular model or Manitoba integrated model (Albtoush et al., 2011). In this study, we have decided to consider the model proposed by Alexander (2002) that divides a crisis response in four main parts: 
- 1 st phase: prevention. This phase takes place before the beginning of a crisis. It aims to decrease both the probability of appearance of the risks related to the crisis and also their consequences if the crisis occurs.

- 2nd phase: preparation. This phase also takes place before the impact. It consists in establishing new processes of response adapted to the future crises.

- $\quad 3 r d$ phase: immediate response. This phase integrates all the actions to be carried out as fast as possible after the impact, such as the release of the crisis plan or the evacuation of a threatened population.

- 4th phase: recovery. This step takes place once the crisis situation is under control. However, the disturbed system needs improvement to return to its nominal state. For example, it may consist in repairing infrastructure or looking after a displaced population.

This brief literature review shows that one critical issue in the management cycle of a crisis is the response phase. Indeed if all of the phases are important, the response phase is the most time-constrained.

Our research project focuses only on the response step of crisis management, but deals with it in depth, in contrast to the research work of Othman and Beydoun (2010) who tackle the whole lifecycle but with only a basic meta-modelling for each phase.

\section{Code knowledge: crisis management meta-model}

Reducing the severity of a crisis by supporting collaborative processes implies identifying the required knowledge to design a relevant and accurate response. The objective of this section is to provide an encompassing and appropriate approach for crisis response modelling. Information embedded into the model should be exploitable, particularly to deduce the relevant collaborative processes and then to build a potential information system interoperability system to support these processes (as was the final objective of the ISyCri project).

As implied in the previous section, the ontology should be organised in two parts: the specification ontology and the response ontology. The first one includes the studied system (including, for example, people, natural site, goods) and the crisis system (containing elements of crisis identification such as type, gravity, trigger). The second one includes the treatment system deployed to reduce the crisis as well as the 
collaborative process executed. By linking conceptually these two parts, we aim to build a global crisis ontology providing a way to produce advanced crisis management tools among them a mediation information system dedicated to crisis situations. Building a crisis meta-model might be a convincing step to create a dedicated crisis ontology that may be able to support reasoning mechanisms. Finally, our meta-model is composed of four interrelated subsystems: (i) the crisis system; (ii) the studied system; (iii) the treatment system and; (iv) the collaborative business processes system. As discussed above in the background and research scope section, we have used UML class diagrams to draw this meta-model.

\section{Crisis system:}

A crisis includes several elements: some (dynamic) are involved in its occurrence or its evolution while others (static) are dedicated to its description. A crisis occurs due to one (or several) trigger(s) and once it appears is composed of three main components: (i) consequence(s); (ii) complexity factor(s) and; (iii) gravity factor(s). A trigger is a kind of event that starts the crisis. It is the realisation of a risk. A consequence is the noticeable consequence of the studied crisis. It is also considered as an event and can produce other consequences. It can be evaluated through indicators. A complexity factor is a danger that impacts the nature of the crisis directly and can affect its type (for instance, a sanitary crisis may evolve into a social crisis due to 'over-communication' through the media). A gravity factor is a danger that directly impacts the gravity of the crisis (for instance, a strong wind and dry weather could affect the seriousness of a forest fire).

The crisis concept is totally in line with the proposal of Bagheri and Gorbani (2010) who term it 'hazard' and the proposal of Othman and Beydoun (2010) who call it 'crisis'. We can note that the concept of consequence appears in the work of Bagheri and Gorbani (2010), but the gravity and complexity factors are not properly addressed by these authors. In Bagheri and Gorbani (2010), this notion seems to be included in a larger sense of 'threat'. But this threat concerns the origin of the crisis as far as the study system is concerned. Thus, we have proposed to separate this concept into two: (i) gravity and complexity factors and; (ii) characteristic of the studied system (See Figure 2).

Figure 1 summarises the meta-model that is proposed to structure the knowledge of the crisis system. 


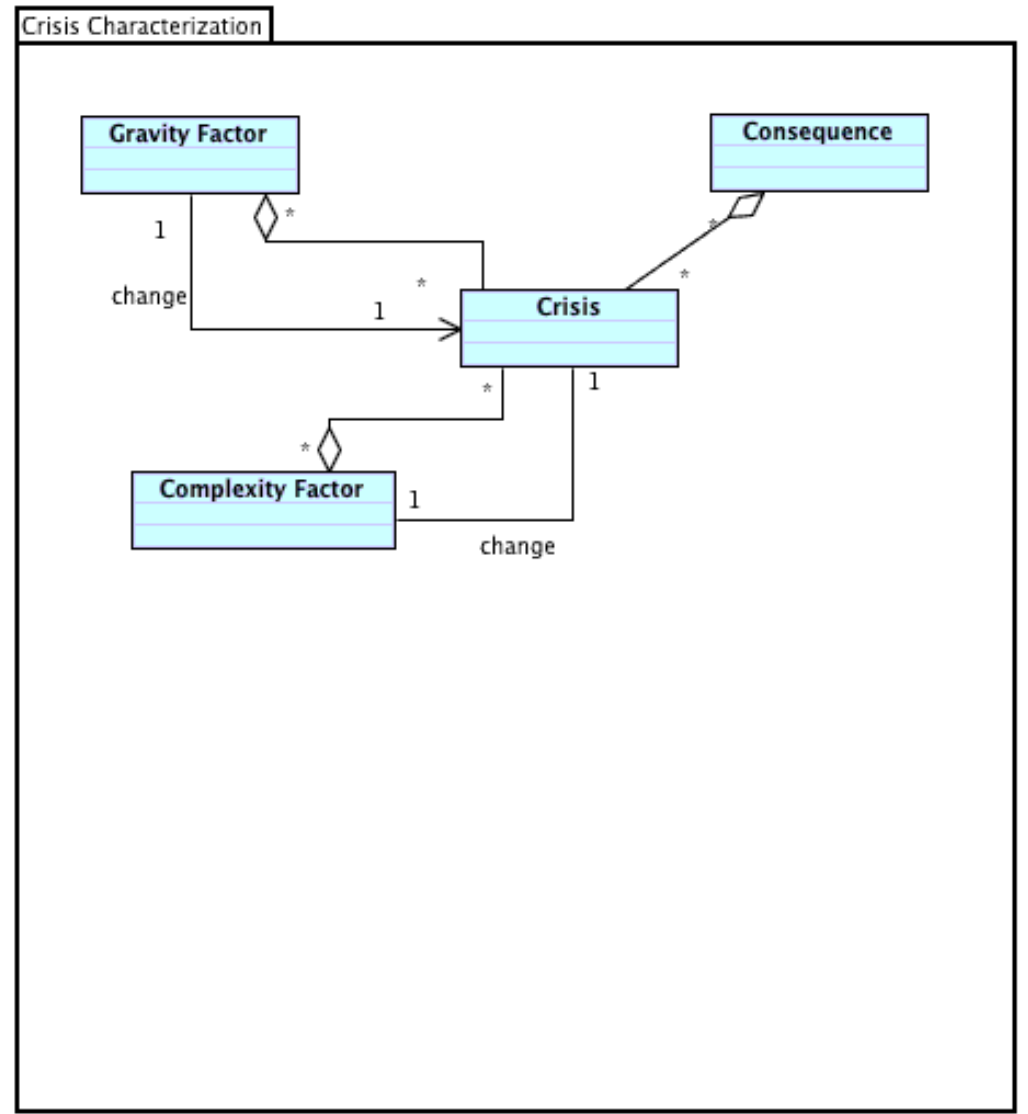

Figure 1. Crisis system meta-model

Source: authors.

\section{The studied system:}

The studied system is defined as the sub-part of the world affected by the crisis. The components of this subsystem have been grouped in different categories such as goods, natural site, people and civil society in order to cover any kind of crisis. All these elements are considered as studied system components that may be concerned by the situation. Goods can be seen as each man-made entity (roads, bridges, buildings, houses). On the other hand, natural sites are the elements of the studied system that are not man-made, such as rivers and forests. People concerns all the persons who are directly (victims) or indirectly threatened by the crisis situation (people of a city, groups of travellers, employees of a company). Civil society includes legal entities (media, intellectuals), associations and organisations that act in the crisis area. The studied system also contains risks and characteristics. The characteristic includes two complementary notions, the vulnerability of the system and the danger to which it is subjected. A characteristic exists continually (on the studied system) and one or several $\operatorname{risk}(s)$ may result from exposure to this characteristic. For instance, an area like the US West Coast presents a characteristic of seismic instability and a low 
vulnerability (comparing with Port-au-Prince in Haiti, for instance) while an earthquake occurrence is a risk attached to this characteristic.

This subsystem constitutes a real added value when compared to related works. For example, Bagheri and Gorbani (2010) only identify the concepts of 'vulnerability' and 'cause' (as a subpart of our event concept) in their meta-models. Moreover, they propose a structure and organisation meta-model that is composed of three concepts (infrastructure, system and task) representing their studied system. But this meta-model is limited only to critical infrastructures and not to any kind of situations. Similarly, Othman and Beydoun (2010) simply defined the concepts of vulnerability (called 'exposure' in their paper) and the concept of victims who need rescue. This last concept is particularly limited because it does not permit study of the incidence of the crisis on the overall population present in the area.

Thus our proposal is coherent with previous works and allows the ontology approach to be generalised to different kinds of crisis, considering not only the victims but the whole ecosystem that is impacted by the crisis and its consequences.

Figure 2 summarises the meta-model that is proposed to structure the knowledge of the studied system. 


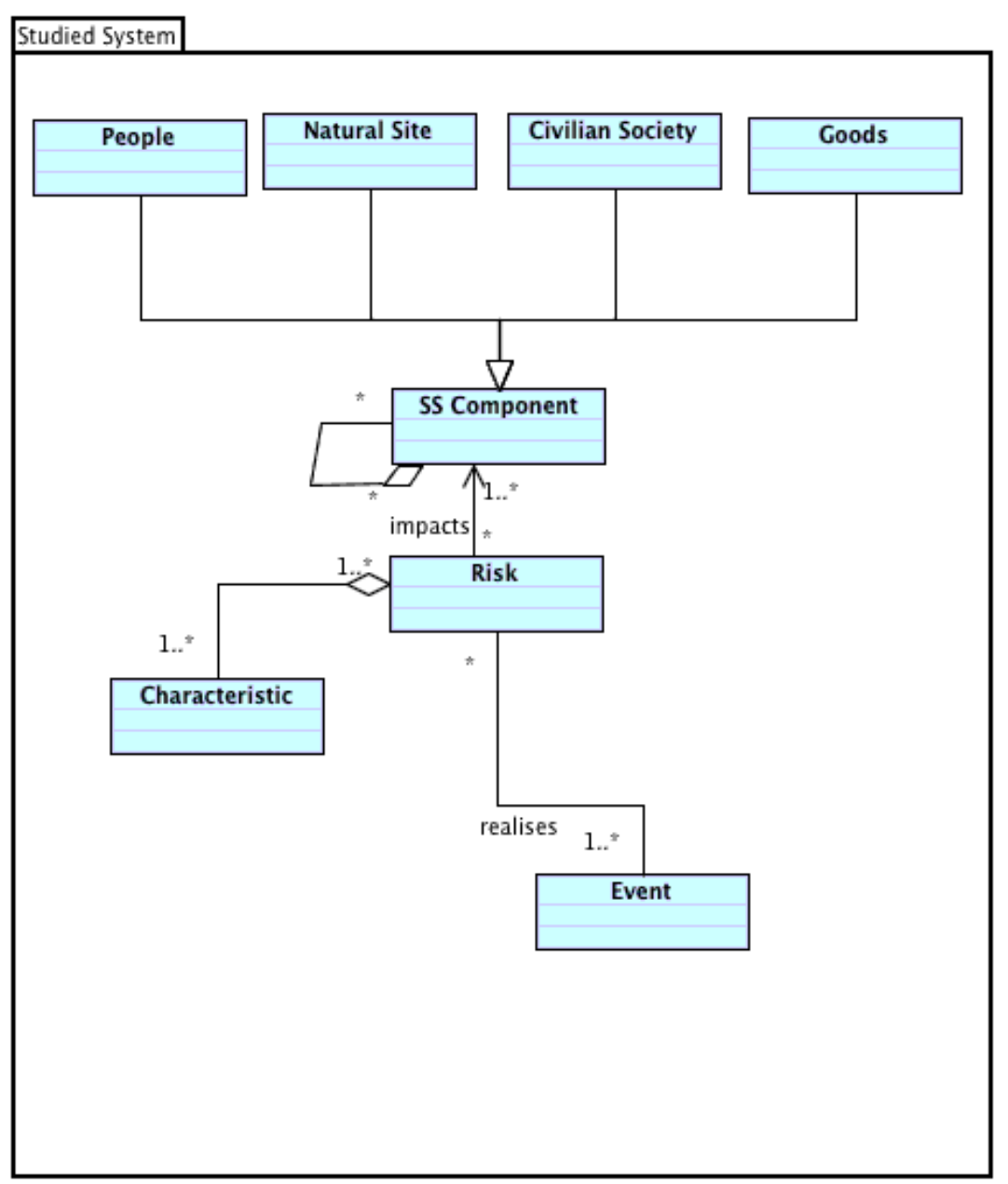

Figure 2. Studied system meta-model

Source: authors.

\section{The treatment system:}

In order to solve (or at least to reduce) the crisis situation, we need to define a treatment system that aims to drive the situation towards a stable and manageable state. As stated earlier, an answer to a crisis can be defined as the set of measures which are taken to solve the problems caused by the appearance of a crisis (Delvin, 2006). Consequently, the definition of a response to a crisis is linked to the notion of 'measures taken'. These measures will be called services, corresponding to the business process activities of stakeholders and in accordance with the serviceorientated architecture approach.

This articulation of the response around the notion of service can be found at the level of the treatment system of the crisis system meta-model. Therefore, the services will be characterised first. Usually two types of services can be distinguished to deal with risk: 
- Preventive: services that reduce the probability of occurrence or the potential consequences. Such services must be run before the appearance of risk.

- Corrective: services that can reduce the consequences of the realisation of one or several risks.

A service can consequently be executed to prevent a risk or to reduce a consequence. Therefore, it uses human or material resources. However, some services need a particular state of the system or of the response to be carried out properly, which we call a condition. Conditions represent a state of the system; they can be put in place or needed by a service. They can also be implicit or automatic between two services. In that case, the links of necessities will be directly defined between the services.

While we have discussed the conditions of realisation of a service, we have not mentioned the cases forbidding it. If certain risks and consequences can obviously forbid a service, a service can also be forbidden by another one. For instance, certain services can be antagonist, in particular at the level of resources.

This set of concepts and relations will help to deduce a response to the crisis that an interoperable information system has to deal with. As mentioned previously, not only can this system guarantee the interoperability between different partners, but it can also propose added-value services. Consequently, we distinguish two types of service: the actor service and the interoperability service. The actor services correspond to the partner's business process services whereas the interoperability services correspond to the interoperability information systems added-value services, such as a service of orchestration or coordination.

Finally, this treatment system includes actors (institutions or other parties, on site or not), their resources (physical or non-physical), the services they provide, their conditions (including prerequisite/post-requisite requirements, one of which is the operating procedures) and their interoperability services. These interoperability services will be executed by the collaborative process when the system will run.

Compared to those described in the existing literature (such as Bagheri and Gorbani, 2010; Othman and Beydoun, 2010; De Nicola et al., 2011), this subsystem is very similar with regard to descriptions of human resources and physical resources. Its originality concerns the service approach and the focus on interoperability services to support collaboration (or coordination) during the crisis response. Othman and Beydoun (2010), for instance, tackle the problem of coordination by defining a UML 
class named 'coordination', but without providing any detail. To reach our goal of supporting interoperability in a crisis situation, we need more information on this class. Consequently we have created a dedicated subsystem that is described in the following section.

Figure 3 summarises the meta-model that is proposed to structure the knowledge of the treatment system.

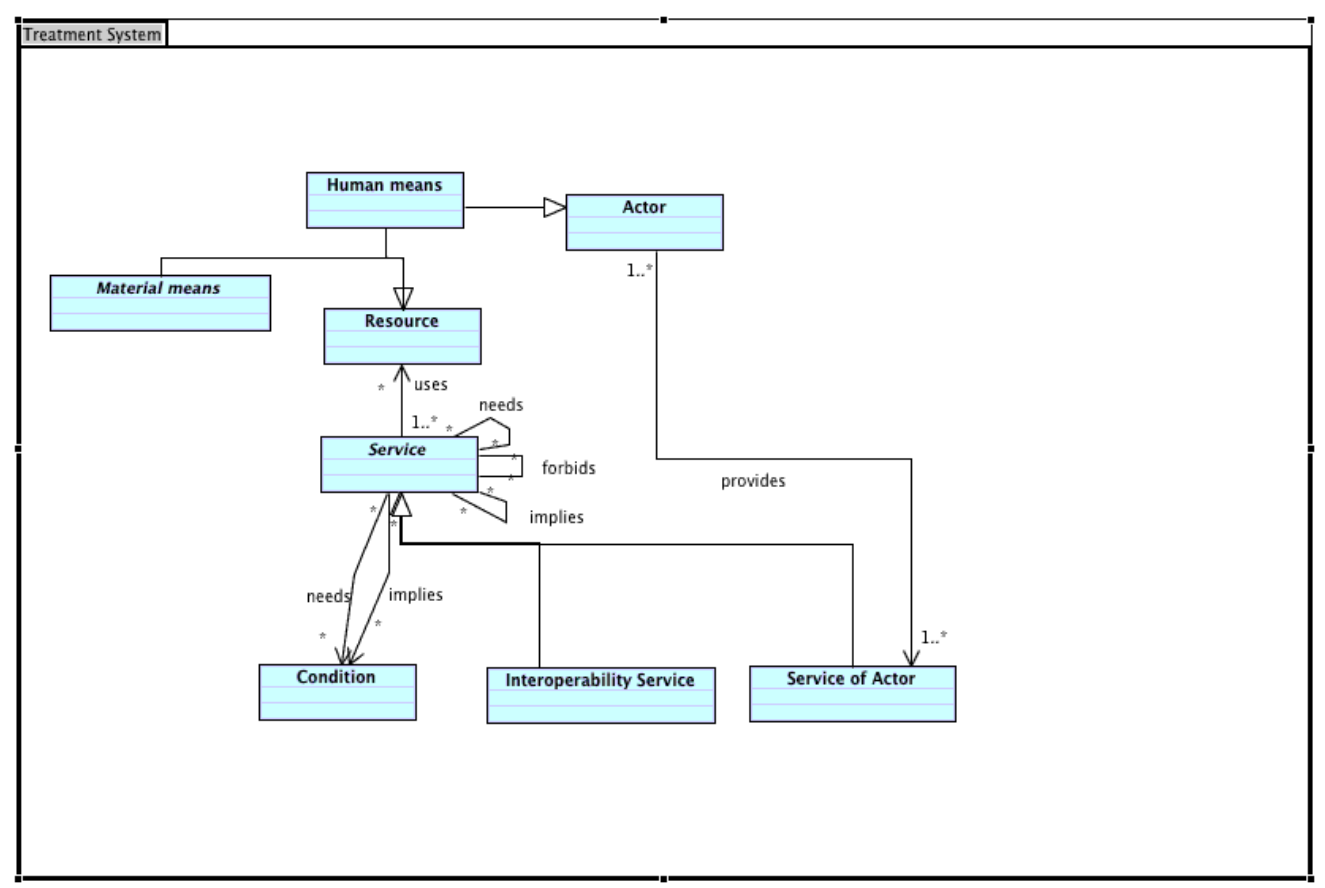

Figure 3. The treatment system meta-model

Source: authors.

\section{The collaborative process meta-model:}

This subsystem is dedicated to the collaborative process description (it includes elements of process modelling) and is directly inspired from BPMI (Business Process Management Institute) standards $^{5}$ and from a meta-model of collaborative process described in (Touzi et al., 2009).

This part of the meta-model proposes a way to represent collaboration by composing a finalised set of activities led by the partners in a response to the crisis in order to solve it. The definition of this viewpoint logically orientated us towards a business-process representation. Many definitions of the notion of business process exist. Let us quote those that seem relevant in relation to our research work:

- Morley (2002) defines a business process as 'the organisation of a finalised set of activities made up by actors involving entities'. 
- Vernadat (1996) proposes another definition about the structure of a business process: 'a business process is a partially orderly set of stages executed in order to realise at least one goal'.

- The norm ISO 9001 (ISO, 2008) defines a business process as 'a set of activities correlated or interactive that transforms input into output'.

These different definitions underline the advantage of using the business process to represent the management of a crisis. The services (equivalent to the activities in the above definitions) carried out by the various partners, are made in an orderly way to make the situation evolve (which corresponds to a transformation of the input system into an output system) towards a steady, objective environment of crisis management.

We mentioned previously that the use of collaborative business processes to respond to the crisis needs an orchestration (that is, activities' sequencing), potentially proposed by an interoperable information system and/or the crisis-cell in charge of the execution of this process via the invocations of services of the contributing partners. It consequently offers a structure of control of all or part of the process communicating between contributing systems. This use of collaborative business processes imposes certain restrictions or characteristics on any process.

Each actor must be represented independently. The activities of the different actors cannot be linked directly; a transition by the mediator is compulsory. Each message sent and received by an actor must be processed to control information at the level of the mediator. The mediator could be an information system and/or a physical stakeholder.

The meta-model below, extracted from the global crisis meta-model and defined by Touzi et al. (2009), describes this collaborative business process. ${ }^{6}$ This is composed of one single pool, called IIS_pool, representing the interoperability information system. The set of logic operators of the process (sequence_flow, gateway, event) defining the succession of activities can only belong to this unique pool. Each partner of the collaboration is represented by a pool. This pool can only contain lanes, each of them representing a division of the actor, which in turn can only contain activities, called partner_task. The service of actor, represented by a partner_task, can be put in relation via messages flows with a service of interoperability, named IIS_task. These messages flows model the transfer of information between the actor and the interoperability system. A service of interoperability is used to transform the data, initially and before the invocation of a 
service of actor, so that the data is sent with the adequate format. The transformation happens a second time when the data is gathered from the service of actor to be stored. The assumption has been made that there is always a flow of information back and forth between the interoperability information system and the partner. Even if the service does not send the information back, we suppose that it at least returns the information of end.

Figure 4 summarises the meta-model that is proposed to structure the knowledge of the collaborative process.

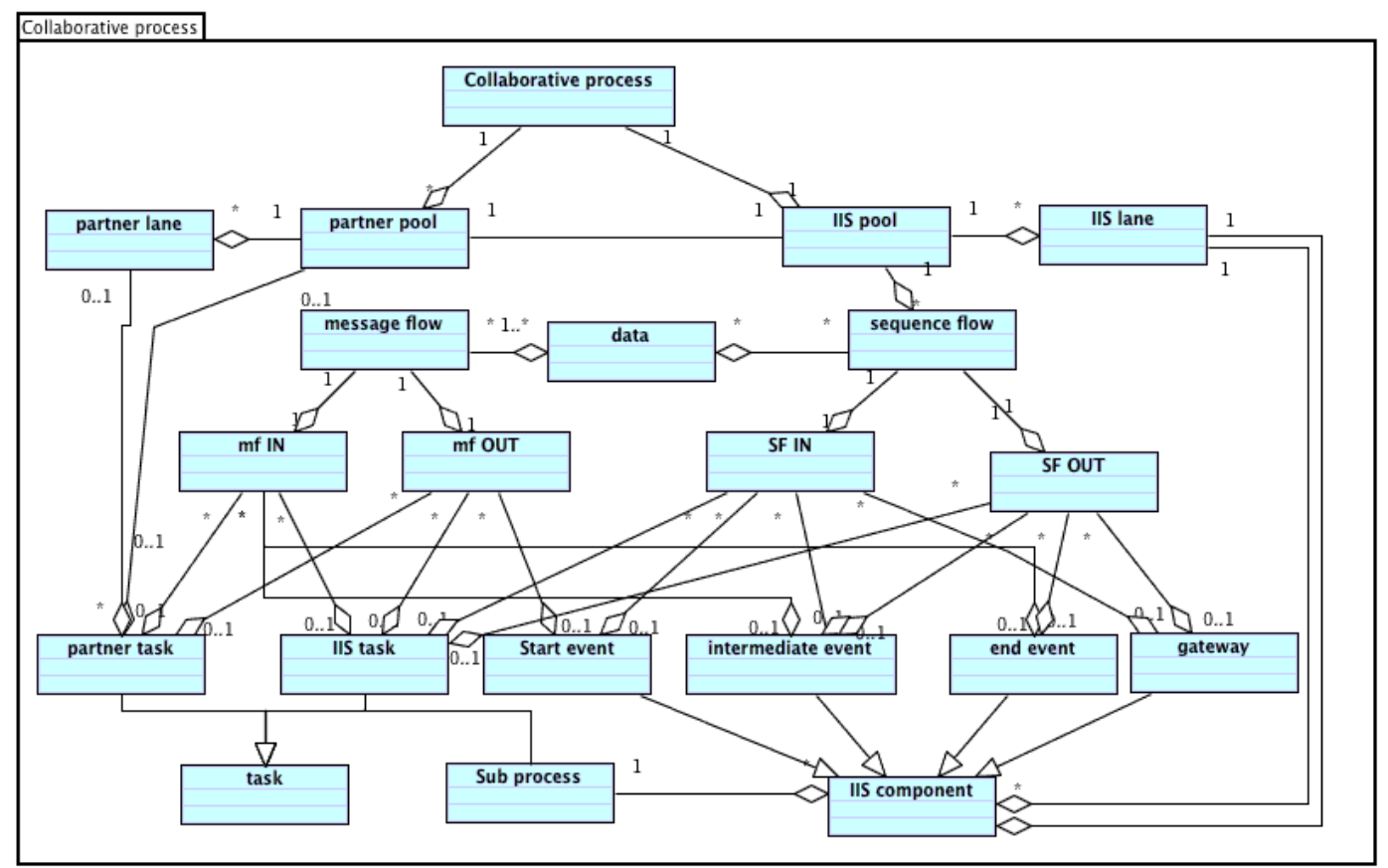

Figure 4. The collaborative process meta-model

Source: authors.

\section{The global crisis management meta-model:}

The different parts of the meta-model that we have just described should be connected to each other. These links are the root of the proposed ontology. The links between the different parts are the following:

Between the situation (studied system and the crisis system) and the treatment system:

- The services are connected with the risks by relations defining that a service can prevent a risk, create a risk, be forbidden by a risk.

- The links of reductions and banning can be connected to a service and a consequence. 
- Obviously, a service can have an impact on the system components of the study. It can destroy goods or displace populations, for instance. The use of a service can also be banned by a component of the system of study. The presence of the population can, for instance, prevent one from using fire-fighting aircrafts.

- The banning of the use of a service can also be due to the presence of a characteristic, of a factor of complexity or of a factor of gravity. For instance, the presence of some media (factor of complexity) can ban the use of a service that may give a bad image of the rescue party.

Between the treatment system and the collaborative process, the links have already been mentioned in the descriptive part of the collaborative process. They are as follows:

- Each actor of the response is represented by a partner_pool.

- According to the nature of the service, their links to the collaborative business process vary. A service of actor will correspond to a partner_task, whereas a service of interoperability will correspond to an IIS_task.

Finally, Figure 5 presents the whole crisis meta-model. 


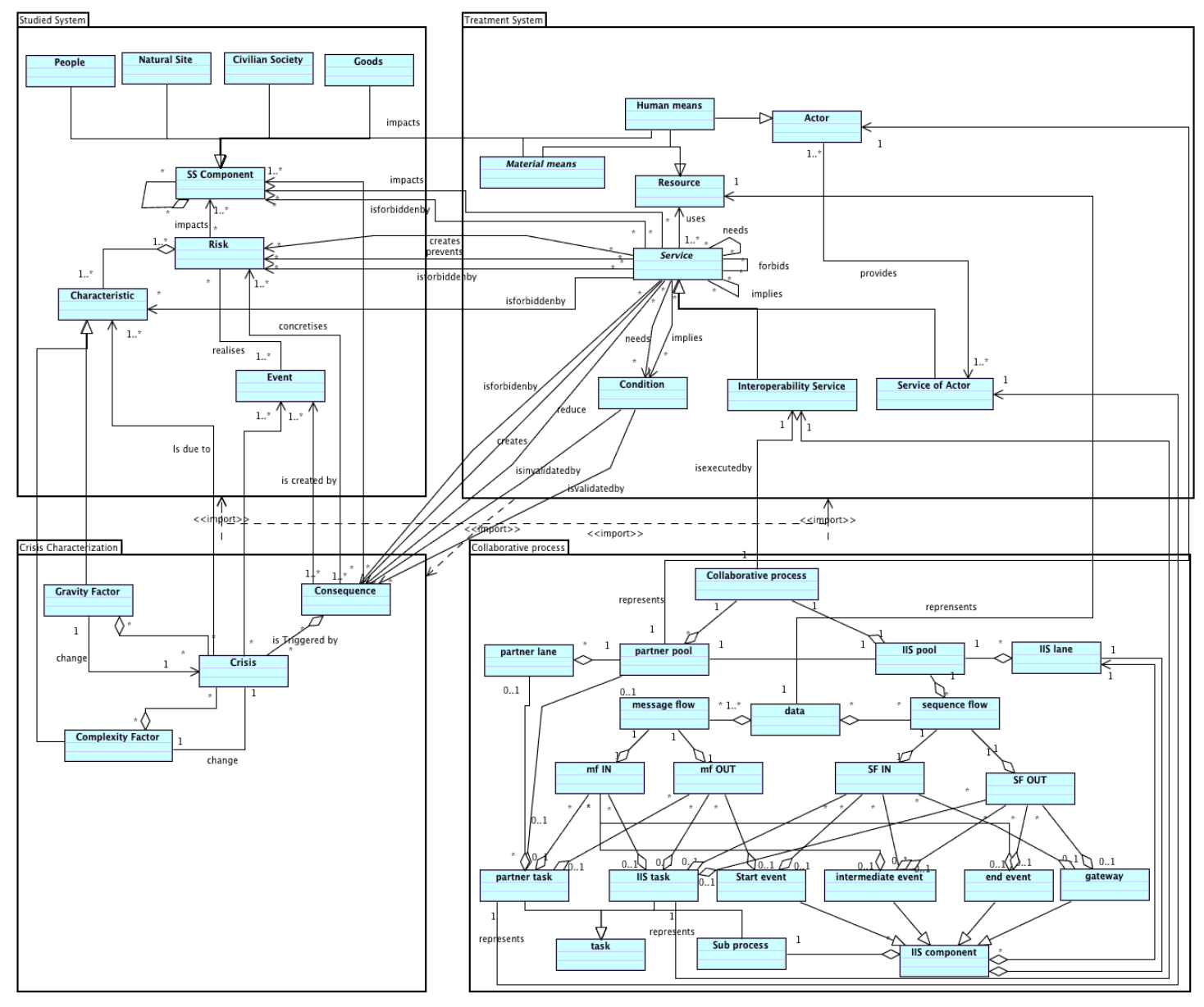

Figure 5. The global crisis meta-model

Source: authors.

\section{Ontological treatments of crisis situations:}

In order to use the knowledge collected in one instance of the proposed meta-model efficiently and as completely as possible, we propose using ontological mechanisms recognised as a suitable method of knowledge management (Missikoff and Taglino, 2006). These concepts may be instantiated in order to create concrete knowledge.

In fact, once defined, our meta-model covers the whole crisis representation but it cannot express the dynamics of such situations. We need to make it more expressive and absolutely non-ambiguous to have its instances processed by a workflow system. One possible approach to meet this requirement is to use descriptive logic-based ontologies. We used the approach and definition given by Gruber (1993) to obtain an ontology that has to be specified as clearly as possible, all concepts being possibly defined axiomatically. So, the main constraint in the building of the ontology was to use only explicit assumptions, excluding any implicit behaviour of the system in order to provide a full and clean model usable by the inferential services we planned to use. Technically speaking, our UML meta-model 
was translated into an OWL-DL ontology. In comparison with OWL-Full or OWLLite (subsets of the same language), OWL-DL offers large expressivity possibilities and is the only ontology that ensures computational completeness and decidability: it is fully usable by a computer programme.

The way of building the ontology from the UML meta-model is derived from Hart and Emery (2004) and Gasevic et al. (2004). Thus we ensure that no information or relation is lost from the UML description. The structures of the ontologies are based on the UML meta-model where each UML class becomes an OWL class. In the same way, UML relationships between classes are OWL properties. The original meta-model was split into two separate ontologies. The first describes the crisis (that is, the crisis system and studied system as described on sub meta-models 1 and 2 presented on Figures 1 and 2) while the second is focused on the resolution process (that is, the treatment system and collaborative processes as described on sub metamodels 3 and 4 presented on Figures 3 and 4). This approach facilitates the maintenance of the whole system, allowing the replacement of the resolution process ontology. Expressiveness is ensured by logical operations such as cardinality restrictions, inclusions, exclusions or equivalences. This set is called the TBox (Terminologic Box). It contains all concepts and roles definitions, as opposed to the ABox (Assertional Box) that contains, among other things, the instances of our model.

This ontology currently covers the full meta-model and the inference mechanism is focused on the resolution processes. In fact, the resolution processes are extracted from well-structured operation guides used in civil crisis management. We chose these in the first instance because they contain the more completed process definitions that we needed to test our model before going on to less-structured process definitions (humanitarian and military crisis resolution, for instance). All the crisis plans we used to build this model are designed and used by the actors of crisis management themselves. This ensures a practical approach to the solutions. There is at least one crisis plan for each kind of crisis. In each plan, there is a file for every single actor involved in crisis management. These files describe the actions the actors should perform and their relationships with other actors or actions. This is the raw material used to build the resolution process ontology. We used Protégé framework to build the ontologies and ensure proper definition of each concept and relation. As a part of a wider software dedicated to the ISyCri project, we also developed a proof of concept software (ISyView) to visualise ontologies as graphs and to exploit them 
using an inference engine. ${ }^{7}$ ISyView, written in Java, embeds a JENA framework and a Pellet inference engine to provide various services around the ontology, such as validation and deduction (see the case study section below). During a crisis, each known fact can be positioned in the ontology (within Protégé) and taken into account by the graph display and the inference engine. It is also possible to prepare, before any crisis, some pre-instantiated models and load them when a crisis appears.

Finally, two core ontologies (crisis system and studied system in one side and treatment system and collaborative process on the other side) can be correlated by semantic rules between their classes to give the ISyCri ontology. Instances of classes would then give the material to apply those rules on tangible crisis resolution.

\section{$\underline{\text { Reuse }}$}

Our approach has been tested and validated, especially through several specific instantiations (Lauras et al., 2008; Truptil, 2011; Truptil et al., 2008). The case study section below develops one example that is based on a transportation crisis. The reader can see more implementation cases (some are in video format) on the following permanent website: http://mise.mines-albi.fr/isycri/.

\section{Evaluation}

Gomez-Pérez et al. (1995) suggest verifying ontology through three complementary verifications:

- Architecture: the definition and the use of the crisis meta-model allow us to validate the architecture of the ontology because it is compliant with the five design criteria given by Gruber (1993): formal aspect, explicit aspect, sharing aspect, conceptualisation aspect, domain specificity.

- Lexis and syntax: in our proposal, each instance corresponds to one concept and solely one. This instance is linked with others only through the relationships defined in the meta-model. Consequently, the verification of lexis and syntax is not relevant in our case.

- Content: although the knowledge is built 'on the fly' and is fully dependent on the evolution of the situation, the use of graphical editors (such as graphical modelling framework [GMF] environment [Steinberg et 
al., 2008]) can ensure that the ontology is syntactically consistent by perfect matching with the crisis meta-model.

\section{Documentation}

In the context of the ISyCri research project, it is quite difficult to describe the knowledge gathered in the ontology because of the crisis and the speed constraint. Consequently we decided to create a dynamic documentation by automatically generating some $\mathrm{html}$ files directly from the ontology. These files are composed of a navigator - which allows the user to navigate between instances - and a description area for each instance of the ontology. This area displays (i) the name, (ii) the description, (iii) links with other instances for a specific instance of the ontology. These files are created when a model is injected into the ontology.

\section{Case study: truck-train crash}

This case study is based on an exercise carried out by the French authorities. The scenario is the following: 'At $10 \mathrm{am}$, on 27th February, the police were informed of an accident between a tanker truck (unknown substance) and a wagon containing chemical products (materialising as a cloud). The policemen who were sent to the scene, and the employees of the railway station, fell unconscious, while several children from the neighbouring kindergarten (who were playing outside when the accident happened) began to feel sick. The engine of the tanker truck exploded.' To summarise, following this collision, some travellers have been injured, a fire has begun, people are burned and an unknown product has escaped from the tanker.

\section{Crisis model: instance of studied system and crisis system}

The crisis cell is composed of four members: state agents, firemen, policemen and the Emergency Medical Service. Once the crisis appears, these decision-makers try to gather information about the situation. Nowadays, this information would be written on a whiteboard. In our approach, the decision-makers create a crisis model, thanks to the crisis-modelling tool, which easily gathers/collects information on the situation in a graphical form and in a way that is understandable and shareable by all the partners. But this objective is not the only one. It should also be possible to use this structured 
knowledge as an input for potential advanced crisis management systems (such as mediation information systems and decision-support systems).

This crisis model, represented in Figure 6, is based on the studied system and crisis system parts of the crisis meta-model. In this model, there is some information concerning the sub-part of the world impacted by the crisis, like goods: tanker, train, railway, road; or people: population, injured people. Among all the risks of this studied system, only risks with a high probability of occurrence (the ones that have been listed by members of the crisis cell) are included, such as risk of fire, risk of contamination, risk of leak, risk of traffic jam, risk of burned people and risk of injured people. Concerning the crisis system part, the model contains, on the one hand, all the known consequences of the crisis, such as burned people, injured people, fire and traffic jam, and on the other hand, all the factors, like the gravity factor of wind (the cloud may move depending on the direction and the strength of the wind, for example) and the complexity factor of a dangerous product transport area.

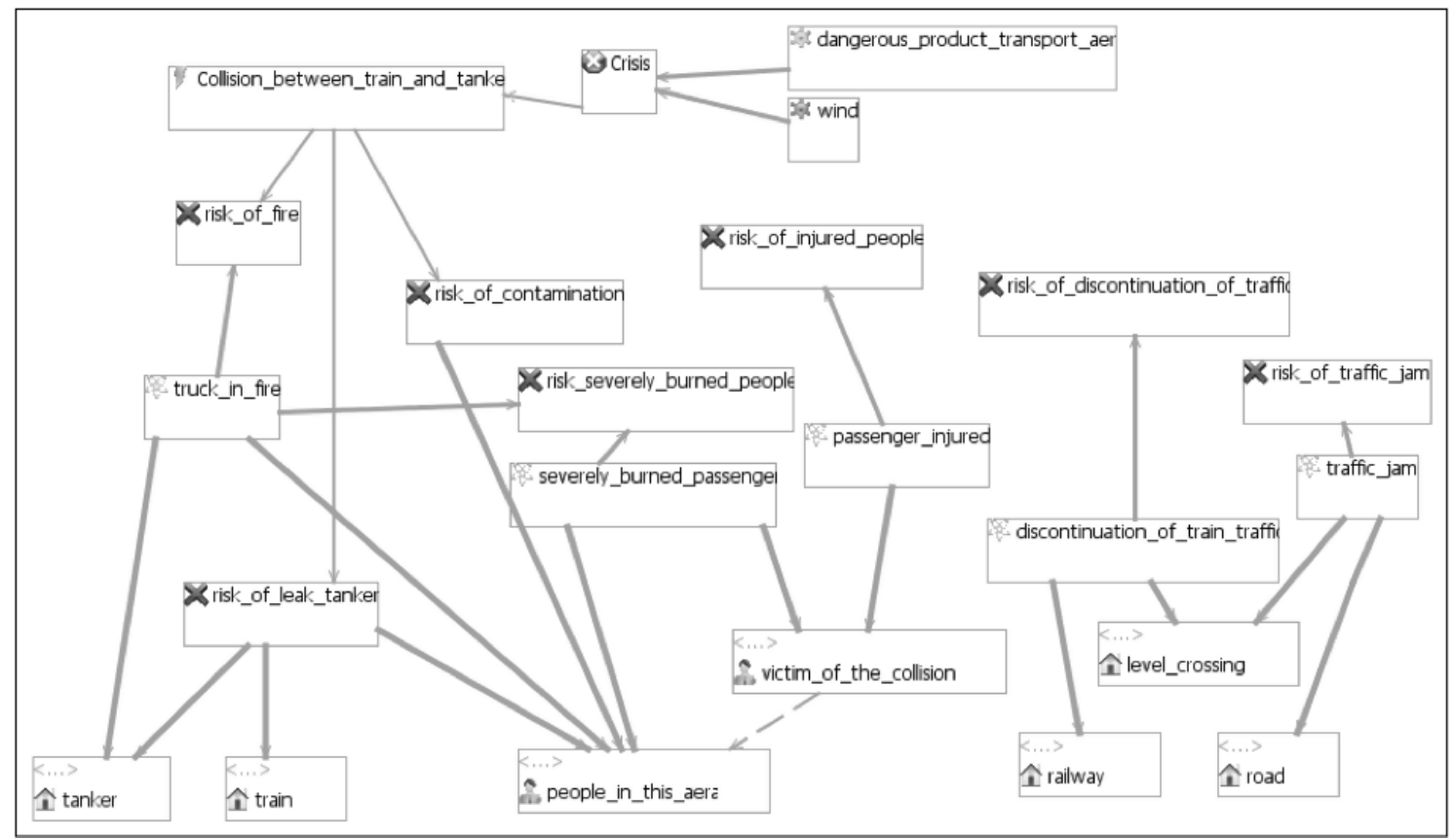

Figure 6. Crisis model respecting the crisis meta-model

Source: authors.

\section{Service model: instance of treatment system}

During the preparation phase of the crisis management lifecycle, each actor needs to create a model that exposes its services. The example in the next figure is a subpart of the service model of firemen. In this kind of model, the actors present their services and choose the description level of these services, even if some of them could be 
divided into several services. Consequently, only these services would appear in the collaborative process.

Some of the services presented by the firemen are the following:

- Transport injured people.

- Provide ambulance, which implies the condition ambulance ready.

- Cool with water, which prevents risk of explosion and needs the service prepare firemen.

- Prepare firemen, which needs the condition area secured.

- Care people, which needs prepare firemen, reduces the consequence injured people, and prevents risk injured people.

- Put out small fire, which needs prepare firemen, prevents risk of fire, reduces the consequence of fire.

- Put out huge fire, which needs prepare firemen, prevents risk of fire, reduces the consequence of huge fire.

Of course, all the other actors involved in this crisis also have services, described in their service model. The crisis cell member Emergency Medical Service for instance has a service called 'carePeople', which prevents the risk of sick people and reduces the consequence of sick people. However, this service needs the service 'prepareTreatment'.

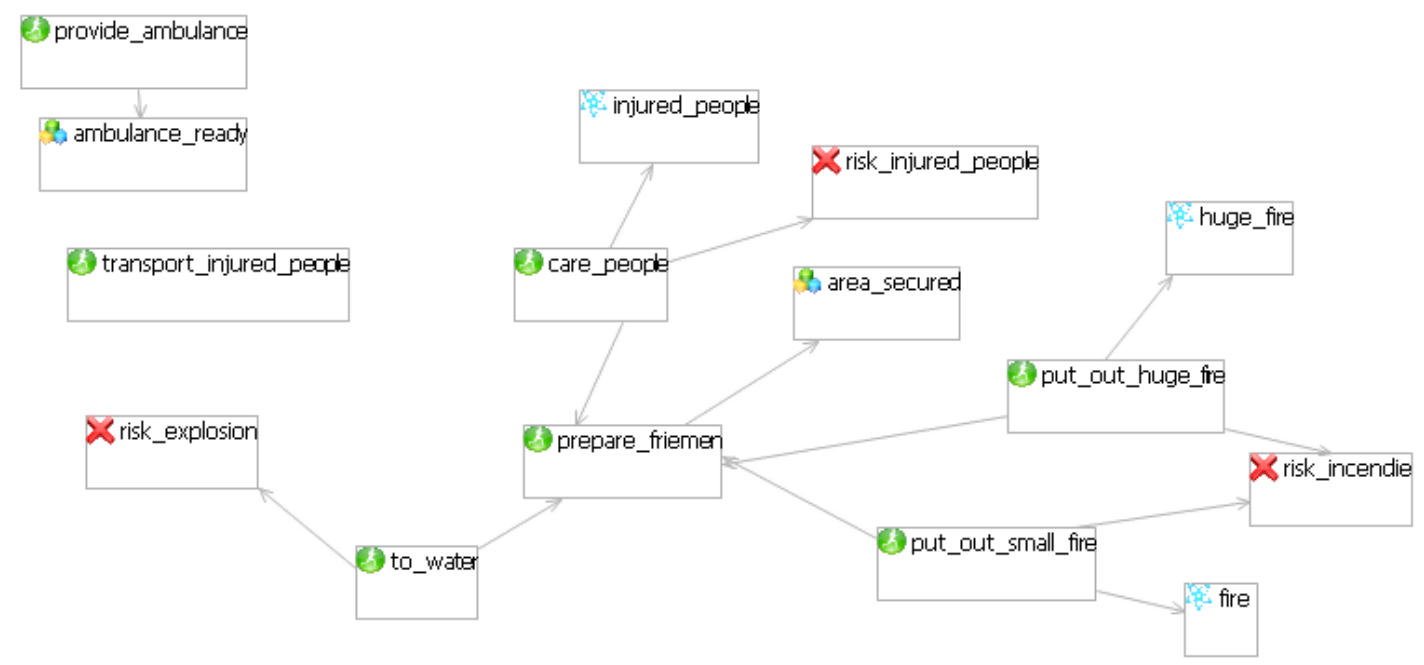

Figure 7. Firemen service model respecting the meta-model

Source: authors. 
At this point, the crisis models and service models produced are injected into the ontology using an XSL transformation. For each instance of the model that has to be injected into the ontology, the following test is done:

If there is no identical instance wording (for the same kind of concept) in the ontology;

then a new instance is created along with its associated links as defined in the model;

otherwise, links to the new instance are created inside the ontology.

Figure 8 shows the obtained ontology after the injection of the two previous models. This figure is created with the IsyView modeller. All instances are linked to their concepts and to other instances. For example, the service of actor care people is linked to the concept service of actor and to the instances prepare firemen, risk of injured people and to the consequence injured people. In spite of the fact that the two last instances are present in the two models, they have a link, called has, with the crisis instance because they are present in the crisis model.

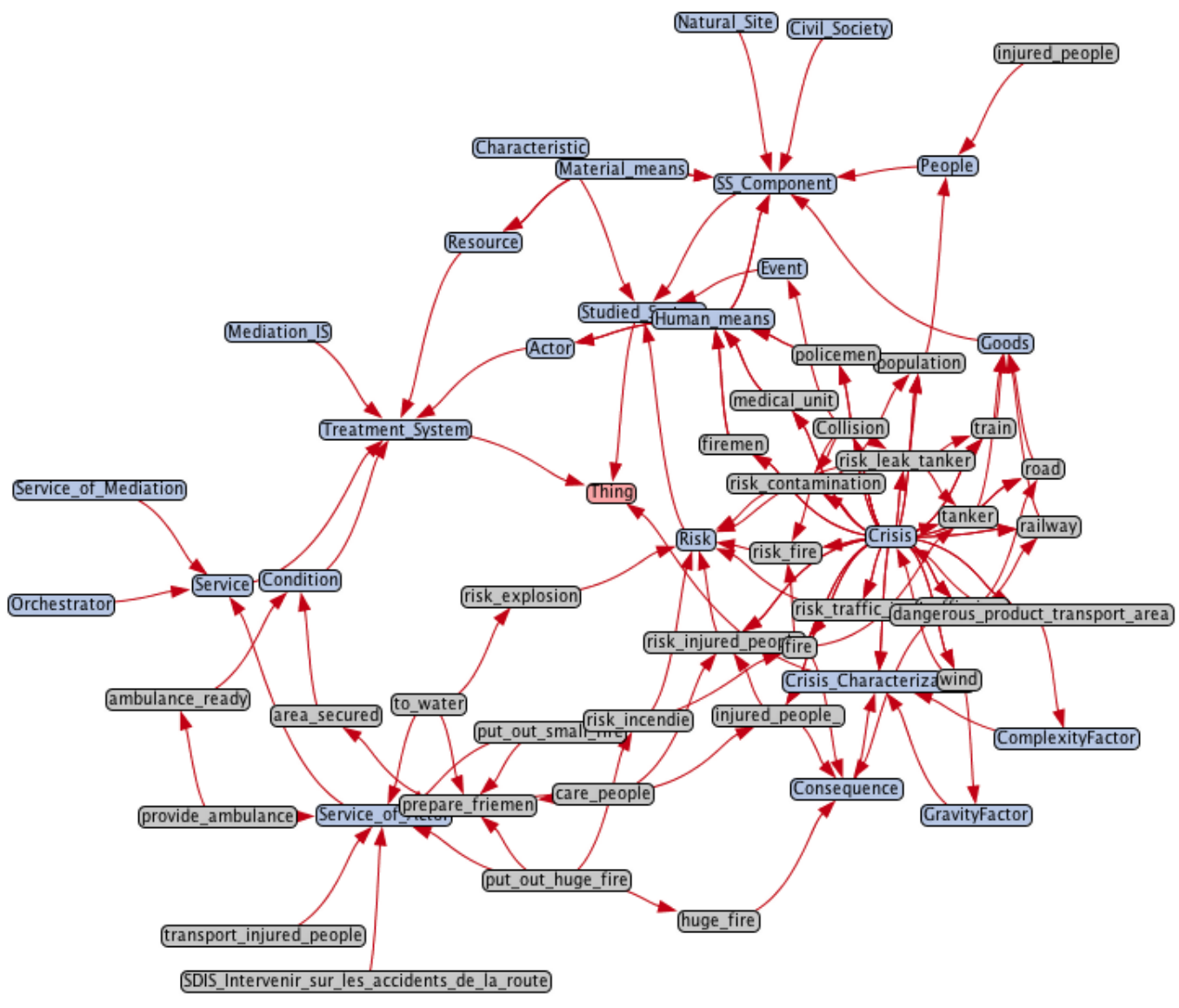

Figure 8. Ontology of the crisis

Source: authors. 


\section{Model of crisis response: instance of the collaborative process}

After the injection of the crisis model and service model of each actor, the ontology can be used to deduce a collaborative process that describes the dynamics of the crisis response. This point is not developed in this paper. See Truptil (2011) or the IsyCri website $^{8}$ for more information on the deduction of collaborative process from the produced knowledge ontology. This is one of a number of potential applications of such an ontology.

\section{Conclusion of the example}

This example aims to illustrate the uses of the crisis meta-model during a response to a crisis. In this context, several actors have to work simultaneously and in a hurry with the shared objective of solving the crisis situation. To carry out this objective, the actors need to coordinate their activities and share data. However, coordination is a difficult exercise in a crisis situation, as explained by Hansen-Glize (2008) and sharing information is a recurrent problem of humanitarian crises. The use of the crisis meta-model allows these difficulties to be overcome. First, each actor can describe his abilities in a way understandable to everyone and all actors of the crisis response can share the same picture of the situation. Second, it is possible to use this structured knowledge to develop and use some advanced crisis management tools. Today, the crisis cell writes on a blackboard information of the situation, as can be seen on the IsyCri website. Thus the crisis cell could easily learn how to create the crisis model. As regards the collaborative process, its creation is assisted (Truptil, 2011). Therefore, the use of tools based on the crisis meta-model could be used in a crisis context.

\section{Conclusions and future works}

We believe that the integration of partners is a crucial step to success in crisis reduction. Our point is to propose a solution to this 'integration of partners' issue by means of knowledge structuration and sharing. This is a crucial objective (due to the human and economic consequences involved) but also a challenging one (due to the cultural, functional and technological heterogeneity of partners and also to the crisis nature of a crisis). Because the fact that a crisis is an evolutionary phenomenon, a particular collaborative response has to be defined for each crisis. Consequently, a 
crisis meta-model and associated ontology have been proposed to facilitate the sharing of knowledge but also to allow in the future the development and the use of advanced crisis management systems (such as decision support systems, mediation information systems, agile systems). They define a framework to keep, compare and reuse information. This paper focuses on the methodology used to define such a metamodel and then develops its characteristics: (i) the studied system, corresponding to the sub-part of the world impacted by the crisis; (ii) the crisis system, corresponding to the properties of a specific crisis; (iii) the treatment system, corresponding to a description of the abilities of actors, which can potentially be implemented in a crisis response; (iv) the collaborative process, corresponding to a description of the crisis response involved. Because information may come from heterogeneous sources in a crisis context, we need to ensure the syntactic validation of the ontology. Consequently, we have developed dedicated modelling tools, which allow users to gather rapidly and confidently information that fits totally with the meta-model on the one hand, and with the ontology syntax on the other. These results have been discussed with regard to the main related works and to a chemical accident case (truck-train crash).

Complementary to previous works such as the OASIS project (http://www.oasisproject.eu/), our proposal constitutes a step towards supporting the problem of coordination and interoperability in a crisis context, in which the modelling tools engender a problem of semantics. If all actors used exactly the same vocabulary, the semantic links between instances of different models would be automatic. But the fact is that a crisis response involves heterogeneous and autonomous stakeholders, and this assumption cannot therefore be objectively maintained. This point constitutes the main perspective for future research work.

\section{Correspondence}

Matthieu Lauras, Toulouse University, Mines-Albi, Industrial Engineering Department, Campus Jarlard, Route de Teillet, 81013 Albi, France. Telephone: +335 634932 16; fax: + 335634931 81; e-mail: lauras@mines-albi.fr. 


\section{References}

Albtoush, R., R. Dobrescu and F. Ionescou (2011) 'A hierarchical model for crisis management systems'. Universitatea Politehnica Bucuresti Sci. Bull Series C, , 73(2), pp. 53-62.

Alexander, D. (2002) Principles of Emergency Planning and Management. Oxford University Press, New York.

Asghar, S., D. Alahakoon and L. Churilov (2006) 'A comprehensive conceptual model for disaster management'. Journal of Humanitarian Assistance. Published at the Department of Peace Studies, University of Bradford, UK, and the Feinstein International Center, pp. $1-15$.

Bagheri, E. and A.A. Ghorbani (2010) 'A Reference Model For Profiling Critical Infrastructure Systems'. Information Systems Frontiers, 12(2), pp. 115 - 139.

Bataille, V. and X. Castellani (2001) 'Métamodélisation et ingénierie des systèmes d'information'. In: C. Cauvet and C. Rosenthal-Sabroux (Eds) Ingénierie des systèmes d'information. pp. 149-174.

Colomb, R.M. and M.N. Ahmad (2010) 'A perdurant ontology for interoperating information systems based on interlocking institutional worlds'. Applied Ontology. $5(1)$, pp. $47-77$.

De Nicola, A., A. Tofani, G. Vicoli and M.L. Villani (2011) 'Modeling collaboration for crisis and emergency management'. Proceedings of The First International Conference on Advanced Collaborative Networks, Systems and Applications, June 1924, 2011 - Luxembourg, pp. 22-27.

Devlin, E. (2006) Crisis Management Planning and Execution. Auerbach Publications, Boca Raton, FL. 
Gasevic, D., D. Djuric, V. Devedzic and V. Damjanovi (2004) 'Converting UML to OWL ontologies'. 13th International World Wide Web Conference. New York, .

Steinberg, D., Budinsky, F., Paternostro, M., and E. Merks (2008) EMF: Eclipse Modeling Framework, The Eclipse Series, 2nd Edition. 744 p.

Gomez-Pérez, A., N. Juristo and J. Pazos (1995) Evaluation and assessment of the knowledge sharing technology, In Mars N (ed) Towards a very large knowledge acquisition workshop, EKAW99, Springer, p. 139-156.

Gruber, T.R. (1993) 'A translation approach to portable ontologies', Knowledge Acquisition, 5(2), pp. 199-220.

Guizzardi, G. (2005) Ontological Foundations for Structural Conceptual Models. Telematica Instituut Fundamental Research Series, No 15, Enschede, The Netherlands.

Hansen-Glize, C. (2008) De la «maîtrise » des crises, In: Management de la Sécurité, Techniques de l'Ingénieur (Ed).

Hart, L. and P. Emery (2004) OWL Full and UML 2.0 compared. Whitepaper (http://www.uk.builder.com/) Version 2.4, 12 March 2004, p. 19.

Henderson-Sellers, B. (2011) 'Bridging metamodels and ontologies in software engineering', Journal of Systems and Software, 84(2), pp. $301-313$.

ISO (2008) ISO 9001 Quality management systems -Requirements. International Standar, Fourth Edition, p. 36.

Jacques, J.M. and L. Gatot (1997) 'De l'incident à la catastrophe: un modèle organisationnel', Urgences Médicales, 16(1), pp. 24-30.

Kovoor Misra, S. (1995) 'A multidimensional approach to crisis preparation for technological organizations: some critical factors', Technological Forecasting and Social Change, 48(1), pp. 143-160. 
Kruchten, P., C.W.K. Monu and M. Sotoodeh (2008) 'A conceptual model of disasters encompassing multiple stakeholder domains', International Journal of Emergency Management, 5(1), pp. 25-56.

Lagadec, P. (1992) La Gestion Des Crises - Outils De Réflexion À L'usage Des Décideurs, Ediscience International, Paris, p. 323.

Lauras, M. et al. (2008) Vers une interopérabilité des systèmes d'information de gestion de crise : analyse d'une crise humanitaire, Proceedings of MOSIM'08, Paris.

Missikoff, M. and F. Taglino (2006) 'Ontologies for interoperability : a systematic overview', Lectures in ECI Workshop, Paris.

Morley, C. (2002) La modélisation des processus: typologie et proposition utilisant UML, Proceedings of Processus et Systèmes d'information-Journées ADELI, Paris, France.

OMG (2003) MDA Guide Version 1.0.1, In: Muller J. and J. Mukerjy (Eds), Object Management Group, p. 62.

Othman, S.H. and G. Beydoun (2010) 'Metamodelling approach towards a disaster management decision support system', In: Springer Verlag (Ed), Proceedings of the 10th International Conference on Artificial Intelligence and Soft Computing, Poland, pp. 614-621.

Pinto, H.S. and J.P. Martins (2004) Ontologies: How can they be built? Knowledge and Information Systems, 6 (4), pp. 441-464.

Rosenthal, U. and M.T. Charles (1989) The Management of Disasters, Riots and Terrorism, In: Lagadec P. (Ed), La gestion des crises, Edisciences, p. 200.

Ruiz, F. and J.R. Hilera (2006) 'Using ontologies in software engineering and technology'. In: C. Calero, F. Ruiz and M. Piattini (eds.) Ontologies for Software Engineering and Software Technology. Springer-Verlag, Berlin. pp. 49-102. 
Sanjay, J. and C. McLean (2003) 'A framework for modeling and simulation for crisis response', In Proceedings of the $35^{\text {th }}$ conference on Winter simulation: driving innovation, New Orleans, USA, pp. 1068-1076.

Silva Parreiras, F. and S. Staab (2010) 'Using ontologies with UML class-based modeling: The TwoUse approach', Data and Knowledge Engineering, 69(1), pp. 1194-1207.

Slobodan, S. and A. Sajjad (2005) 'Computer-based Model for Flood Evacuation Emergency Planning' Natural Hazards, 34(1), pp. 25 - 51..

Sugumaran, V. and V.C. Storey (2002) 'Ontologies for conceptual modeling: their creation, use and management', Data \& Knowledge Engineering, 42(1), pp. 251-271.

Tomasini, R. and L.N. Van Wassenhove (2009) Humanitarian logistics, Palgrave Macmillan, p. 192.

Touzi, J., F. Benaben, H. Pingaud and J.P. Lorré (2009) 'A model-driven approach for collaborative service-oriented architecture design', International Journal of Production Economics, 121(1), p.5-20.

Truptil, S. (2011) Etude de l'approche de l'interopérabilité par médiation dans le cadre d'une dynamique de collaboration, $\mathrm{PhD}$ Thesis, Institut National Polytechnique de Toulouse, p. 208.

Truptil, S. et al. (2008) 'Interoperability of Information Systems in Crisis Management: Crisis Modeling and Metamodeling', Proceedings od the I-ESA'08 conference, Berlin, Allemagne.

Uschold, M. (2005) 'An ontology research pipeline', Applied Ontology, (1)1, pp.1316.

Uschold, M. and M. King (1995) 'Towards a methodology for building ontologies’ 
In: Proceedings of IJCAI95's workshop on basic ontological issues in knowledge sharing, Montreal, Canada

Vernadat, F.B. (1996) Enterprise Modelling and Integration, principles and applications, Chapman \& Hall, p. 592.

W3C Incubator Group (2008) Emergency Information Interoperability Frameworks, Technical Report.

Zhang, D., L. Zhou and J.F. Nunamaker Jr (2002) A knowledge management framework for the support of decision making in humanitarian assistance/disaster relief, Knowledge and Information Systems, 4(1), pp. 370-385. 
Appendix. List of concepts and their definitions

\begin{tabular}{|c|c|}
\hline Concept & Definition \\
\hline Actor & Role that a human resource assumes. \\
\hline Characteristic & $\begin{array}{l}\text { Includes two complementary notions: the vulnerability of the system and } \\
\text { the danger to which it is subjected. }\end{array}$ \\
\hline $\begin{array}{l}\text { Civilian } \\
\text { society }\end{array}$ & $\begin{array}{l}\text { Individuals and organisations in a society, which are not directly involved } \\
\text { in the crisis. }\end{array}$ \\
\hline $\begin{array}{l}\text { Collaborative } \\
\text { process }\end{array}$ & Set of sequencing activities between two or more actors. \\
\hline Condition & Prerequisites and post-requisites that a service needs. \\
\hline Consequence & Noticeable impact of the studied crisis. \\
\hline Crisis & $\begin{array}{l}\text { Linked to the perception of an abnormal situation, which is a break in the } \\
\text { expected evolution of the situation (standard, planned or at least acceptable) } \\
\text { of the world or part of the world concerned by the phenomenon (the studied } \\
\text { system). }\end{array}$ \\
\hline Data & Is a set of raw values (qualitative or quantitative). \\
\hline End event & Represents the result of a process. \\
\hline Event & An observable occurrence of something (more or less important). \\
\hline $\begin{array}{l}\text { Factor of } \\
\text { complexity }\end{array}$ & $\begin{array}{l}\text { Special danger that may imply the modification of the crisis complexity or } \\
\text { even create another pole to the crisis. }\end{array}$ \\
\hline $\begin{array}{l}\text { Factor of } \\
\text { gravity }\end{array}$ & Special danger that may imply the modification of the gravity of the crisis. \\
\hline Gateway & $\begin{array}{l}\text { Determines forking and merging of paths, depending on the conditions } \\
\text { expressed. }\end{array}$ \\
\hline Goods & $\begin{array}{l}\text { Potential items, facilities and materials impacted by the crisis or its } \\
\text { response. }\end{array}$ \\
\hline Human means & Human resources that are involved in responding to the crisis. \\
\hline IIS lane & $\begin{array}{l}\text { Represents interoperability information systems' roles and functionalities } \\
\text { that are used. }\end{array}$ \\
\hline IIS pool & Represents major interoperability information systems that are involving. \\
\hline $\begin{array}{l}\text { Intermediate } \\
\text { event }\end{array}$ & Represents something that happens between the start and end events. \\
\hline $\begin{array}{l}\text { Interoperability } \\
\text { service }\end{array}$ & $\begin{array}{l}\text { Interoperability information systems added-value services, such as a service } \\
\text { of orchestration or coordination. }\end{array}$ \\
\hline Material means & Material resources that are used to respond to the crisis. \\
\hline Message flow & $\begin{array}{l}\text { It tells us what messages flow across organisational boundaries (that is, } \\
\text { between pools). }\end{array}$ \\
\hline
\end{tabular}




\begin{tabular}{|c|c|}
\hline Natural site & Potential impacted natural site (near the crisis or the response). \\
\hline Partner lane & $\begin{array}{l}\text { Used to organise and categorise activities within a pool according to } \\
\text { function or role. }\end{array}$ \\
\hline Partner pool & $\begin{array}{l}\text { Represents major participants in a process, typically separating different } \\
\text { organisations. A pool contains one or more lanes. }\end{array}$ \\
\hline People & $\begin{array}{l}\text { Potential people concerned by the crisis (such as victims and persons who } \\
\text { are in the zone). }\end{array}$ \\
\hline Resource & Set of resources that are used to respond to the crisis (human and material). \\
\hline Risk & $\begin{array}{l}\text { Possibility of the occurrence of an event having positive or negative } \\
\text { consequences. }\end{array}$ \\
\hline Sequence flow & Shows in which order the activities are performed. \\
\hline Service & $\begin{array}{l}\text { Measures that are taken to solve the problems caused by the appearance of a } \\
\text { crisis. }\end{array}$ \\
\hline $\begin{array}{l}\text { Service of } \\
\text { actor }\end{array}$ & Know-how of a stakeholder. \\
\hline SS component & $\begin{array}{l}\text { Studied system component that includes people, natural site, civilian society } \\
\text { or goods. }\end{array}$ \\
\hline Start event & Acts as a process trigger. \\
\hline Sub-process & Used to hide or reveal additional levels of business process detail. \\
\hline Task & $\begin{array}{l}\text { Single unit of work that is not or cannot be broken down to a further level } \\
\text { of business process detail without diagramming the steps in a procedure }\end{array}$ \\
\hline
\end{tabular}

\section{Endnotes}

1 Matthieu Lauras is Associate-Professor, Sébastien Truptil is Assistant-Professor and Frédérick Bénaben is Associate-Professor in the Industrial Engineering Department, Toulouse University, Mines-Albi, France.

${ }^{2}$ This research work does not consider the mitigation, preparedness or recovery phases. See the sub-section 'Capture knowledge' within the section 'Crisis management ontology building' below.

${ }^{3}$ Unified modelling language, a standard formalism from OMG dedicated to object-orientated modelling of systems.

${ }^{4}$ PRIM is a French institutional website for major risks prevention (see http://www.prim.net).

${ }^{5}$ See the BPMI website: http://bpmi.org. 
${ }^{6}$ The model proposed by Touzi et al. (2009) is rather more detailed than the three previous ones developed in this paper. We have preferred to keep this level of detail in order not to misrepresent the authors' purpose.

${ }^{7}$ This functionality would have been directly done with the Protégé ontology visualisation plugin.

${ }^{8}$ See the IsyCri website: http://mise.mines-albi.fr/isycri/. 